\title{
C5 Palsy in Cervical Decompression Surgeries: A Study in 390 Patients
}

\author{
Shankar Acharya ${ }^{1}$ Nagendra Palukuri ${ }^{1}$ \\ ${ }^{1}$ Department of Spine Surgery, Sir Gangaram Hospital, \\ New Delhi, India \\ Indian J Neurosurg 2016;5:69-74.

\begin{abstract}
Address for correspondence Nagendra Palukuri, MS, DNB, Department of Spine Surgery, Sir Gangaram Hospital, Room No.
\end{abstract} \\ 1216, New Delhi 110060, India (e-mail: nagendra558@gmail.com).
}

\begin{abstract}
Keywords

- C5 palsy

- cervical decompression

- myelopathy

Introduction C5 palsy following cervical decompression is a known complication. The exact incidence is unclear, due to varying definitions in literature. C5 palsy is associated with significant morbidity due to weakness of deltoid/biceps.

Aim To report incidence of postoperative C5 palsy in cervical decompression surgeries for myelopathy and its correlation with demographic factors, etiology, radiological factors, and to assess recovery of palsy.

Materials and Methods All patients who underwent cervical decompression surgeries from 2006 to 2015 in a single institute were reviewed. A postoperative decrease by $\geq 1$ manual muscle testing grade in only C5 myotome (deltoid/biceps/ both) is taken as positive. Demographic, radiological, surgical factors resulting in C5 palsy and time of onset, duration of symptoms, and degree of recovery were noted. Results A total of 390 patients were included in the study. Out of which, 232 patients underwent anterior while 158 had posterior surgeries. In all, 72 patients had ossification of the posterior longitudinal ligament (OPLL) and rest had spondylotic myelopathy. Incidence of palsy was $6.3 \%$ and mean onset of palsy was 2.8 days. Mean duration for recovery was 6.3 months with near complete recovery seen in majority of the patients $(9 / 10)$. No significant relation was noted with age, preoperative Japanese Orthopedic Association score, change in cervical lordosis, and C45 intervertebral angle. Posterior surgeries, laminectomy, C45 foraminal stenosis, and OPLL were seen as risk factors for C5 palsy.

Conclusion Cervical decompression surgeries are relatively safe, with a small risk of C5 palsy. Though majority of patients recover with conservative treatment, preoperative counseling of this complication has to be explained.
\end{abstract}

\section{Introduction}

Cervical spondylotic myelopathy affects the middle to elderly population, causing significant morbidity. Keegan ${ }^{1}$ first described the $\mathrm{C} 5$ nerve palsy that developed following posterior decompression surgeries as a "dissociated motor loss." C5 palsy causes significant morbidity to patients, making them unable to perform their daily activities. ${ }^{2,3}$ Both

received

June 30, 2016

accepted

July 1, 2016

published online

August 23, 2016
DOI http://dx.doi.org/

$10.1055 / \mathrm{s}-0036-1586742$. ISSN 2277-954X. anterior and posterior decompression surgeries can cause this complication. ${ }^{4,5}$ Controversy still exists regarding the incidence, cause, risk factors, and measures to prevent C5 palsy. Incidence varied between 0 to $26.4 \%$ in anterior surgeries and 0 to $50 \%$ in posterior surgeries. ${ }^{6}$ Here, we tried to study the incidence in both anterior and posterior surgeries as well as identify various risk factors that lead to development of $\mathrm{C} 5$ nerve palsy.
(C) 2016 Neurological Surgeons' Society of India
License terms

(요 (1) $\Theta$ 

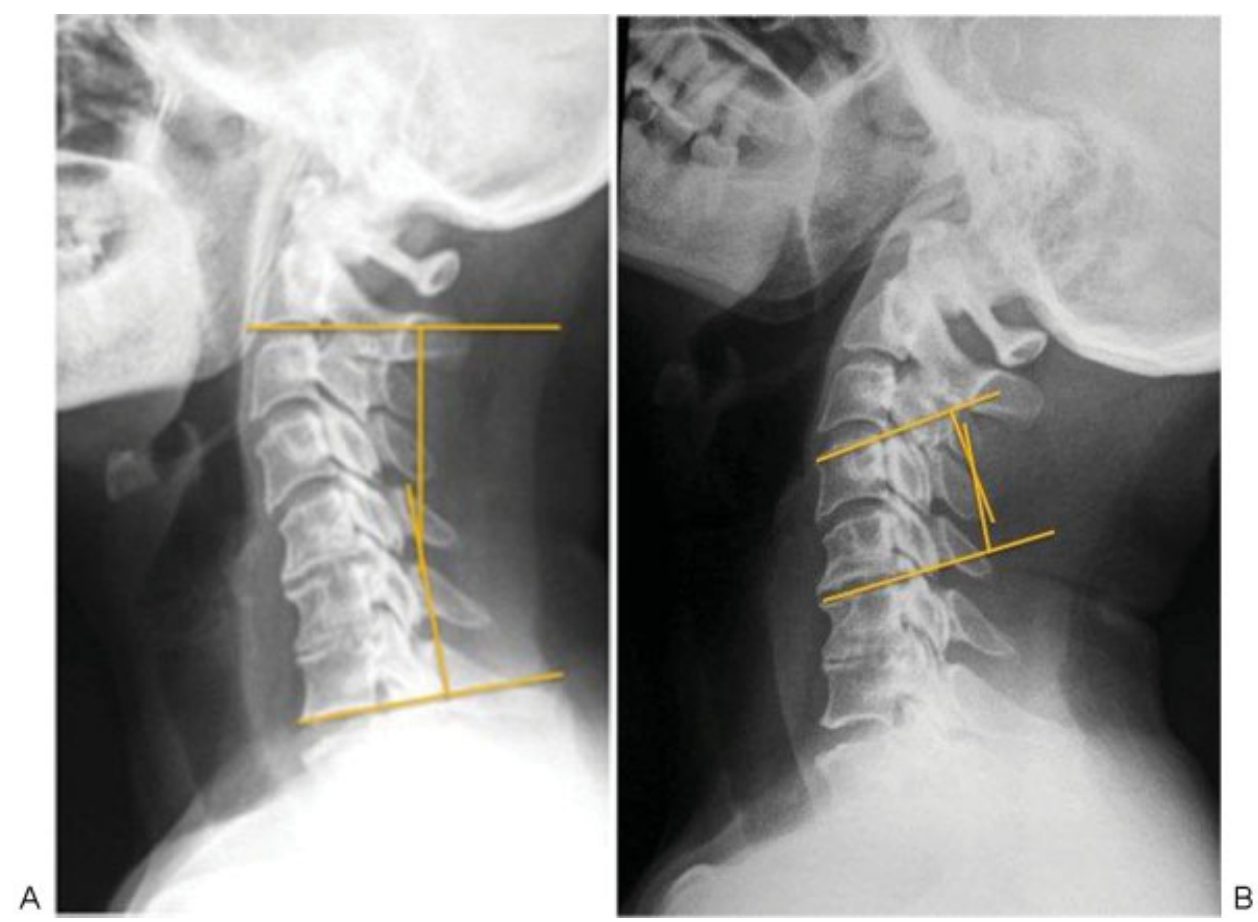

Fig. 1 (A) Measurement of cervical lordosis and (B) C45 intervertebral angle.

\section{Patients and Methods}

Retrospective analysis of all patient records who were admitted between the year 2006 and 2015 with a diagnosis of cervical compressive myelopathy was performed. All cases included in this study had surgery involving C4-5 segment. Patients who underwent either anterior or posterior surgery were included. Patients who underwent both anterior and posterior surgeries, previous cervical surgeries, those with trauma, infection, or inflammatory disorders were excluded.

Demographic and clinical features of each patient were recorded. These included age, gender, diagnosis, preoperative Japanese Orthopedic Association (JOA) score and Nurick grade, surgery performed, and final JOA score and Nurick grade. All patients who developed weakness in power of deltoid and/or biceps by $\geq 1$ manual muscle testing (MMT) grade, without involvement of other muscles or worsening of myelopathy were included in the palsy group, rest all patients were included in the non-palsy group.

Preoperative and postoperative cervical Cobb angle (C2-C7) and C4-5 intervertebral angle is obtained from lateral radiographs (-Figs. 1 and 2 ). From axial computed tomography (CT) scan, C4-5 foramen width was measured at its narrowest point.

Two senior spine surgeons with a minimum experience of 15 years performed all the surgeries and clinical assessments. Two spine residents, who were blinded to the C5 palsy status, performed all the measurements. No neuromonitoring was used and steel burr with saline at room temperature was used in all cases.

In patients with C5 palsy, onset, duration, treatment given, and level of recovery at final follow-up was noted.
Comparison was made between palsy and non-palsy groups to identify the factors that would predict C5 palsy following decompression surgeries. Change in overall lordosis (Cobb angle) and intervertebral angle was correlated for incidence of C5 palsy. C45 foramen width on the palsy side was compared with contralateral side, and the mean width was compared between palsy and non-palsy groups.

Comparisons were also made between patients with ossification of the posterior longitudinal ligament (OPLL) and all other patients as well as between anterior and posterior surgeries.

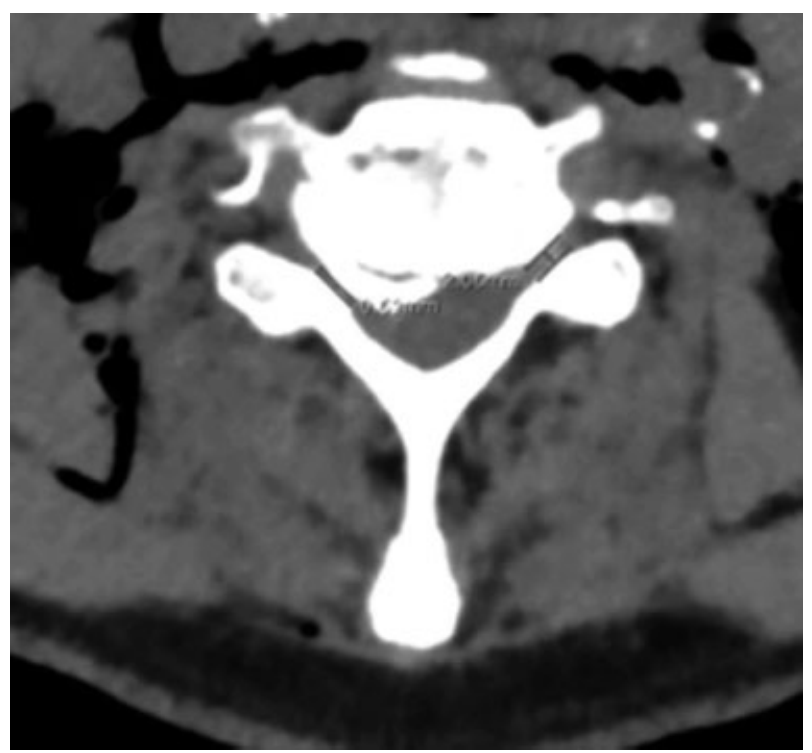

Fig. 2 Width of $\mathrm{C} 5$ foramen, measured at narrowest point on axial computed tomography scan. 
Table 1 Characteristics of patients in palsy and non-palsy group

\begin{tabular}{|l|l|l|}
\hline & Palsy group & Non-palsy group \\
\hline Age (mean) & 55.9 y & 62.3 y \\
\hline Gender ratio (M:F) & $1: 1$ & $1.2: 1$ \\
\hline Total no. of patients & 10 & 380 \\
\hline Disease & 6 & 66 \\
\hline OPLL & 4 & 314 \\
\hline CSM & \multicolumn{2}{|l}{} \\
\hline JOA (mean) & 11.4 & 10.4 \\
\hline Pre-op & 13.3 & 12.3 \\
\hline At final follow-up & \multicolumn{2}{|l}{} \\
\hline Nurick grade (mean) & 2.5 & 3.0 \\
\hline Pre-op & 1.7 & 2.2 \\
\hline At final follow-up & \multicolumn{2}{|l}{} \\
\hline Surgeries & 0 & 128 \\
\hline ACDF & 0 & 104 \\
\hline ACCF & 2 & 42 \\
\hline Laminoplasty & 6 & 27 \\
\hline Laminectomy & 2 & \\
\hline $\begin{array}{l}\text { Laminectomy } \\
\text { with fixation }\end{array}$ & & \\
\hline
\end{tabular}

Abbreviations: ACCF, anterior cervical corpectomy and fusion; ACDF, anterior cervical discectomy and fusion; CSM, cervical spondylotic myelopathy; F, female; JOA, Japanese Orthopedic Association; M, male; OPLL, ossification of the posterior longitudinal ligament.

\section{Results}

From 2006 to 2015, we identified 421 patients who underwent surgery for cervical compressive myelopathy, out of which 31 patients were excluded (214 were males and 176 were females). A total of 72 patients had OPLL and rest 318 patients had cervical spondylotic myelopathy (CSM).

In the CSM group, 205 patients underwent anterior surgery, while 113 patients underwent posterior surgery and in the OPLL group, 27 patients underwent anterior surgery while 45 underwent posterior surgery. A total of 10 patients developed C5 palsy out of which 6 were males and 4 were females. Mean age of patients in palsy group was 55.9 years. Out of these 10 patients, 6 had OPLL, while 4 had CSM. Characteristics of patients in both palsy and non-palsy group are shown in -Table $\mathbf{1}$. The details of patients with C5 palsy are shown in - Table 2 .

\section{Analysis}

Surgical procedure: A total of 232 patients underwent anterior surgery, out of which 128 had anterior cervical discectomy and fusion (ACDF) (53 were single level, 75 were double level) and 104 patients had single-level anterior cervical corpectomy and fusion (ACCF). Out of 232 patients who underwent anterior surgeries, 27 patients had OPLL

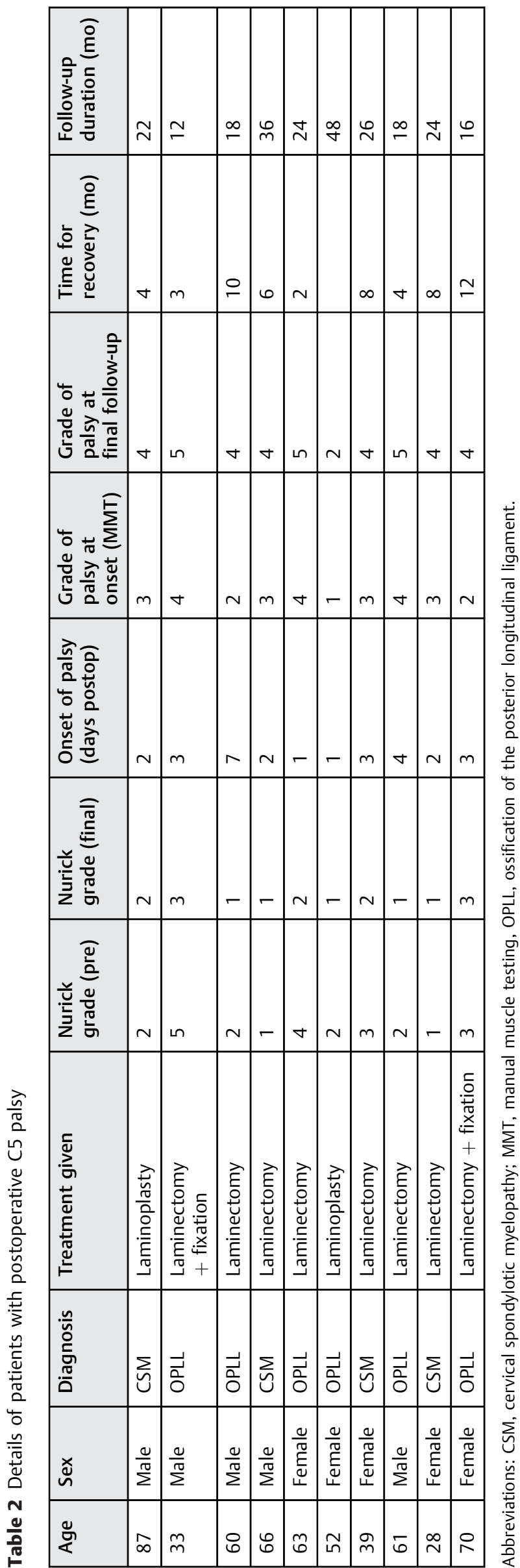


72 C5 Palsy in Cervical Decompression Surgeries Acharya, Palukuri

Table 3 Preoperative and postoperative radiological changes in both palsy and non-palsy group

\begin{tabular}{|l|l|l|l|l|}
\hline \multicolumn{2}{|l|}{ Palsy group } & Non-palsy group \\
\hline & $\begin{array}{l}\text { Pre-op value } \\
\text { (degrees) }\end{array}$ & $\begin{array}{l}\text { Post-op value } \\
\text { (degrees) }\end{array}$ & $\begin{array}{l}\text { Pre-op value } \\
\text { (degrees) }\end{array}$ & $\begin{array}{l}\text { Post-op value } \\
\text { (degrees) }\end{array}$ \\
\hline Cervical lordosis & - & - & 12.1 & 20.5 \\
\hline ACDF & - & - & 8.1 & 19.7 \\
\hline ACCF & -52 & 22.3 & 26.5 \\
\hline Laminoplasty & 22 & 22.5 & 28.7 & 29.4 \\
\hline Laminectomy & 18.3 & 21 & 4.3 & 25.6 \\
\hline Laminectomy with fixation & 10 & 18 & \multicolumn{2}{l|}{} \\
\hline C45 intervertebral angle & - & - & 2.15 & 5.65 \\
\hline ACDF & - & - & 2.43 & 4.95 \\
\hline ACCF & - & 12.5 & 2.9 & 6 \\
\hline Laminoplasty & 12.5 & 12.5 & 5.45 & 7.24 \\
\hline Laminectomy & 10.5 & 7.5 & -0.5 & 5 \\
\hline Laminectomy with fixation & 3 & \multicolumn{2}{l}{} \\
\hline
\end{tabular}

Abbreviations: ACCF, anterior cervical corpectomy and fusion; ACDF, anterior cervical discectomy and fusion.

while rest had CSM. None of these patients developed palsy of $\mathrm{C} 5$ nerve.

Out of 158 patients who underwent posterior surgery, laminectomy was performed in 85 patients, laminoplasty in 44 patients, and laminectomy with posterior instrumented fusion in 29 patients. Out of 158 patients, those with OPLL and CSM were 45 and 113, respectively. In all, 10 patients developed C5 nerve root palsy postoperatively, out of which 2 patients underwent laminoplasty, 6 patients had laminectomy, and 2 patients had laminectomy with instrumented fusion. Palsy was higher in those with OPLL (8.3 VS. $1.25 \%$ in CSM), which was statistically significant.

Radiological: Mean preoperative cervical lordosis in palsy and non-palsy groups was 17.4 degree and 7.5 degree, respectively. Mean change in cervical lordosis following ACDF and ACCF was 8.4 degree and 11.5 degree, respectively. Following laminectomy, laminoplasty, and laminectomy with fusion, the change in cervical lordosis was 0.7 degree, 4.2 degree, and 21.3 degree, respectively. Mean C45 intervertebral angle preoperatively in palsy and non-palsy group was 9.4 degree and 2.5 degree, respectively. Mean postoperative C45 intervertebral angle in palsy and nonpalsy group was 11.5 degree and 5.9 degree, respectively. The mean change in the cervical lordosis and intervertebral angle between palsy group and non-palsy group was not significant. The preoperative and postoperative radiological measurements in both the groups are shown in - Table 3 .

Mean C45 foramen width ( - Table 4 ) in palsy group was $2.85 \mathrm{~mm}$ and in non-palsy group was $4.12 \mathrm{~mm}$, which was statistically significant $(p<0.01)$. Mean foramen width on the palsy side was significantly less as compared with contralateral foramen width (2.5 VS. $3.29 \mathrm{~mm}$ ). Side of the palsy correlated with side of narrow foramen in $80 \%(8 / 10)$ of the patients. In $70 \%$ (7/10) of the patients in palsy group, the foramen width on palsy side was $<3 \mathrm{~mm}$.
C5 palsy: Onset of palsy was seen after a mean postoperative period of 2.8 days and mean MMT grade at time of onset was 2.9. All the patients were managed conservatively with rest, physiotherapy, nonsteroidal antiinflammatory drugs, and corticosteroids in cases with severe palsy (MMT $\leq 2$ ). All except one patient recovered to MMT $\geq$ 4 after a mean duration of 6.3 months, at final follow-up the mean MMT score was 4.1.

\section{Discussion}

Anterior and posterior decompression surgeries are relatively safe with good results in myelopathy patients. ${ }^{4}$ C5 palsy is one serious complication, which causes significant morbidity to patient due to weakness of deltoid muscle with or without involvement of biceps. ${ }^{7}$ In a recent meta-analysis, ${ }^{6}$ the incidence varied from 0 to $26.4 \%$ in anterior surgeries and from 0 to $50 \%$ in posterior surgeries. One cause for this wide variation is due to lack of a standard definition; all patients with decrease in deltoid \pm biceps power without involvement of other muscles by one or more MMT grade were reviewed in our study. In our study of 390 patients, 10 patients developed palsy involving C5 nerve root postoperatively.

Table 4 C45 foramen width as measured in CT scan at narrowest point in various groups

\begin{tabular}{|l|l|}
\hline C45 foramen width (mean) \\
\hline Palsy side & Contralateral side \\
\hline $2.5 \mathrm{~mm}$ & $3.2 \mathrm{~mm}$ \\
\hline Palsy group & Non-palsy group \\
\hline $2.85 \mathrm{~mm}$ & $4.12 \mathrm{~mm}$ \\
\hline
\end{tabular}

Abbreviation: $\mathrm{CT}$, computed tomography. 
Several causes have been suggested, first of which was inadvertent nerve injury by Satomi et al. ${ }^{4}$ But with improvements in surgical technique and technology, there was no significant reduction in C5 palsy incidence. ${ }^{8}$ In a study by Tanaka et $\mathrm{al}^{9}{ }^{9}$ no abnormal events were observed during surgery with intraoperative neuromonitoring. Hence, this theory no longer holds true. Tanaka $\mathrm{N}$ et $\mathrm{al}^{9}$ and Hojo et $\mathrm{al}^{10}$ proposed that increased cervical curvature was a risk factor of C5 palsy in posterior surgery and Wang et $\mathrm{al}^{11}$ proposed the same in anterior surgeries. In our study, mean change in lordosis for anterior procedures was 9.95 degree (in ACDF, 8.4 degree and in ACCF, 11.5 degree) which was significantly more than the preoperative values, but none of the patients developed C5 palsy. Mean increase in curvature following posterior procedures was 8.7 degree, which was not statistically significant when compared with preoperative values.

Local lordotic angle (C45 intervertebral angle) was proposed to cause foraminal stenosis, leading to C5 palsy. ${ }^{12,13}$ The mean change in intervertebral angle following anterior and posterior surgeries was 7.07 and 20.78 degree, respectively. The change was significant in anterior and laminectomy with fusion group, but not in laminectomy or laminoplasty group. Though there was a $6.9 \%$ incidence of palsy in laminectomy with fusion group, it was $0 \%$ in anterior procedures; hence a change in C45 intervertebral lordotic angle in itself would not be a significant risk factor.

Posterior shift of the cord following decompression surgeries is the most common proposed theory for C5 palsy. Posterior shift in the cord is seen after both anterior ${ }^{14}$ and posterior surgeries. ${ }^{15,16}$ Shift of the cord leads to anchoring of nerve root against the superior articular facet, ${ }^{17}$ and C5 nerve root being short, located at apex of lordosis and horizontal course makes it more prone for palsy compared with other nerve roots. ${ }^{17,18}$ Laminectomy involves removal of the entire posterior arch, thus allowing more posterior shift of cord. Radcliff et al noted a higher incidence of C5 palsy in patients who underwent laminectomy as compared with laminoplasty. ${ }^{19}$ In our study, the incidence of palsy in laminectomy group was 7\% and in laminoplasty group was $4.5 \%$. This was statistically significant $(p<0.01)$. In patients who undergo a posterior decompression, those with OPLL may have a more posterior shift of cord compared with those without OPLL. Here, those with OPLL and posterior surgery had a higher incidence of palsy compared with those without OPLL (13 VS. 3.5\%), which was statistically significant $(p=0.04)$. No measurement for the posterior cord shift was done in our study.

Imagama et $\mathrm{al}^{20}$ reviewed 1,858 patients who underwent laminoplasty and found that C4-5 foramen is significantly smaller in the palsy group. In our study, C4-5 foramen width on palsy side was compared with contralateral side and nonpalsy group. Mean width of the foramen was significantly less on the palsy side when compared with the non-palsy side (2.5 VS. $3.2 \mathrm{~mm}$ ) and the side of narrow foramen corresponded to the side of palsy in $80 \%$ of the patients. Also, the mean foramen width in palsy group was significantly less compared with non-palsy group (2.85 VS. $4.12 \mathrm{~mm}$ ). On this basis, preoperative identification of susceptible patients may be done, and a prophylactic foraminotomy would prevent a serious C5 palsy. None of the patient in ours study underwent concomitant foraminotomy. Sasai et $\mathrm{al}^{21}$ and Yanase et $\mathrm{al}^{22}$ reported that preoperative electromyography's could detect a pre-existing radiculopathy and a concomitant foraminotomy might prevent palsy. Komagata et $\mathrm{al}^{23}$ in a review of 305 patients reported a significant reduction in C5 palsy in the group of patients who underwent prophylactic foraminotomy.

Hosono et $\mathrm{al}^{24}$ proposed that the heat generated intraoperatively by high-speed drill caused $\mathrm{C} 5$ palsy as the temperatures rose to $174^{\circ} \mathrm{C}$ with diamond burr and to $77^{\circ} \mathrm{C}$ with steel burr. They reported a higher incidence of $\mathrm{C} 5$ palsy in the diamond burr group. Takenaka et $\mathrm{al}^{25}$ who noted a significant (82\%) decrease in the incidence of $C 5$ palsy by intraoperative irrigation with cold saline while drilling, strengthened this theory. But, the decrease in incidence was only in the early onset group, hence mechanisms other than heat were supposed to cause C5 palsy. All the surgeries in our study were performed using steel burr with saline at room temperature.

On the basis of the appearance of high intensity areas (HIA) on postoperative magnetic resonance imaging (MRI) in patients with $\mathrm{C} 5$ palsy, Chiba et $\mathrm{al}^{26}$ proposed that local reperfusion of the cord could cause C5 palsy; furthermore, the level of HIA corresponded to the level of palsy. Few authors also reported the appearance of HIA on postoperative MRI of patients with palsy, ${ }^{27}$; however, this theory could not explain the unilateral palsy in majority of patients.

Out of 44 patients who underwent laminoplasty, 2 developed C5 palsy. Palsy was seen on the opening side in both the patients, but the difference was not significant statistically. In our study, all patients underwent only opendoor laminoplasty, and thus no conclusion could be drawn regarding the technique of palsy.

Other risk factors proposed were old age, ${ }^{14,28}$ male gender, ${ }^{19}$ severity of myelopathy (or JOA score), ${ }^{8}$ and number of decompression levels. ${ }^{29}$ The mean age in palsy group and non-palsy group was 55.962 .3 years, mean preoperative JOA score of patients in palsy group and nonpalsy group was 11.410 .4 , male to female ratio in palsy and non-palsy groups was $1: 1$ and $1.2: 1$, respectively; the differences in neither was statistically significant. Bose et $\mathrm{al}^{30}$ concluded that intraoperative neuromonitoring with simultaneous sphincter electromyography and transcranial motor evoked potentials can be effective in preventing C5 palsy, but the studies by Fan et $\mathrm{al}^{31}$ and Inoue et $\mathrm{al}^{32}$ showed no proof that incidence of $\mathrm{C} 5$ palsy could be minimized with neuromonitoring. Satisfactory recovery was achieved with conservative treatment in majority (90\%) of the patients in our study; no revision surgery was performed. One patient had persistent palsy at final follow-up. Limitations of our study are less number in the palsy group, no direct measurement of posterior shift of cord, and retrospective nature of study. 


\section{Conclusion}

Age, preoperative JOA score, change in cervical lordosis, and C4-5 intervertebral angle does not appear to be associated with C5 palsy. Posterior surgeries (as compared with anterior surgeries), laminectomy (as compared with laminoplasty), C45 foraminal stenosis, and OPLL were seen to be risk factors for C5 nerve root palsy. No one factor explains the palsy in all cases, and hence the cause is multifactorial. Prophylactic foraminotomy in patients with narrow C45 foramen may prevent this severe complication. Majority of patients recovered with conservative management.

\section{Funding}

No financial support was received for this study.

\section{References}

1 Keegan JJ. The cause of dissociated motor loss in the upper extremity with cervical spondylosis. J Neurosurg 1965;23(5): 528-536

2 Scoville WB. Cervical spondylosis treated by bilateral facetectomy and laminectomy. J Neurosurg 1961;18:423-428

3 Stoops WL, King RB. Neural complications of cervical spondylosis: their response to laminectomy and foramenotomy. J Neurosurg 1962;19:986-999

4 Satomi K, Nishu Y, Kohno T, Hirabayashi K. Long-term follow-up studies of open-door expansive laminoplasty for cervical stenotic myelopathy. Spine 1994;19(5):507-510

5 Zhao X, Xue Y, Pan F, et al. Extensive laminectomy for the treatment of ossification of the posterior longitudinal ligament in the cervical spine. Arch Orthop Trauma Surg 2012;132(2): 203-209

6 Guzman JZ, Baird EO, Fields AC, et al. C5 nerve root palsy following decompression of the cervical spine: a systematic evaluation of the literature. Bone Joint J 2014;96$\mathrm{B}(7)$ :950-955

7 Miller JA, Lubelski D, Alvin MD, Benzel EC, Mroz TE. C5 palsy after posterior cervical decompression and fusion: cost and quality-oflife implications. Spine J 2014;14(12):2854-2860

8 Hasegawa K, Homma T, Chiba Y. Upper extremity palsy following cervical decompression surgery results from a transient spinal cord lesion. Spine 2007;32(6):E197-E202

9 Tanaka N, Nakanishi K, Fujiwara Y, Kamei N, Ochi M. Postoperative segmental C5 palsy after cervical laminoplasty may occur without intraoperative nerve injury: a prospective study with transcranial electric motor-evoked potentials. Spine 2006;31(26):3013-3017

10 Hojo Y, Ito M, Abumi K, et al. A late neurological complication following posterior correction surgery of severe cervical kyphosis. Eur Spine J 2011;20(6):890-898

11 Wang H, Zhang X, Lv B, et al. Analysis of correlative risk factors for C5 palsy after anterior cervical decompression and fusion. Int J Clin Exp Med 2015;8(3):3983-3991

12 Minoda Y, Nakamura H, Konishi S, et al. Palsy of the C5 nerve root after midsagittal-splitting laminoplasty of the cervical spine. Spine 2003;28(11):1123-1127
13 David KS, Rao RD. Bilateral C5 motor paralysis following anterior cervical surgery-a case report. Clin Neurol Neurosurg 2006; 108(7):675-681

14 Saunders RL. On the pathogenesis of the radiculopathy complicating multilevel corpectomy. Neurosurgery 1995;37(3): 408-412, discussion 412-413

15 Hatta Y, Shiraishi T, Hase $\mathrm{H}$, et al. Is posterior spinal cord shifting by extensive posterior decompression clinically significant for multisegmental cervical spondylotic myelopathy? Spine 2005; 30(21):2414-2419

16 Shiozaki T, Otsuka H, Nakata Y, et al. Spinal cord shift on magnetic resonance imaging at 24 hours after cervical laminoplasty. Spine 2009;34(3):274-279

17 Yonenobu K, Hosono N, Iwasaki M, Asano M, Ono K. Neurologic complications of surgery for cervical compression myelopathy. Spine 1991;16(11):1277-1282

18 Currier BL. Neurological complications of cervical spine surgery: C5 palsy and intraoperative monitoring. Spine 2012;37(5):E328-E334

19 Radcliff KE, Limthongkul W, Kepler CK, et al. Cervical laminectomy width and spinal cord drift are risk factors for postoperative C5 palsy. J Spinal Disord Tech 2014;27(2):86-92

20 Imagama S, Matsuyama Y, Yukawa Y, et al; Nagoya Spine Group. C5 palsy after cervical laminoplasty: a multicentre study. J Bone Joint Surg Br 2010;92(3):393-400

21 Sasai K, Saito T, Akagi S, Kato I, Ohnari H, Iida H. Preventing C5 palsy after laminoplasty. Spine 2003;28(17):1972-1977

22 Yanase M, Matsuyama Y, Mori K, et al. Intraoperative spinal cord monitoring of C5 palsy after cervical laminoplasty. J Spinal Disord Tech 2010;23(3):170-175

23 Komagata M, Nishiyama M, Endo K, Ikegami H, Tanaka S, Imakiire A. Prophylaxis of C5 palsy after cervical expansive laminoplasty by bilateral partial foraminotomy. Spine J 2004;4(6):650-655

24 Hosono N, Miwa T, Mukai Y, Takenaka S, Makino T, Fuji T. Potential risk of thermal damage to cervical nerve roots by a high-speed drill. J Bone Joint Surg Br 2009;91(11):1541-1544

25 Takenaka S, Hosono N, Mukai Y, Miwa T, Fuji T. The use of cooled saline during bone drilling to reduce the incidence of upper-limb palsy after cervical laminoplasty: clinical article. J Neurosurg Spine 2013;19(4):420-427

26 Chiba K, Toyama Y, Matsumoto M, Maruiwa H, Watanabe M, Hirabayashi K. Segmental motor paralysis after expansive opendoor laminoplasty. Spine 2002;27(19):2108-2115

27 Wada E, Yonenobu K, Suzuki S, Kanazawa A, Ochi T. Can intramedullary signal change on magnetic resonance imaging predict surgical outcome in cervical spondylotic myelopathy? Spine 1999;24(5):455-461, discussion 462

28 Frykholm R. Lower cervical nerve roots and their investments. Acta Chir Scand 1951;101(6):457-471

29 Yang CW, Fuh JL. C5 palsy after cervical spine decompression surgery. J Chin Med Assoc 2013;76(7):363-364

30 Bose B, Sestokas AK, Schwartz DM. Neurophysiological detection of iatrogenic C-5 nerve deficit during anterior cervical spinal surgery. J Neurosurg Spine 2007;6(5):381-385

31 Fan D, Schwartz DM, Vaccaro AR, Hilibrand AS, Albert TJ Intraoperative neurophysiologic detection of iatrogenic C5 nerve root injury during laminectomy for cervical compression myelopathy. Spine 2002;27(22):2499-2502

32 Inoue S, Tani T, Taniguchi S. The motor-evoked potentials elicited from the deltoid muscle by transcranial magnetic stimulation with a standardized facilitation: the potential diagnostic utility for C5 radiculopathy. Spine (Phila Pa 1976) 2003;28(3):276-278 